\title{
Leucocytes and Th-associated cytokine profile of HIV-leishmaniasis coinfected patients attending the Abuja Teaching Hospital, Nigeria
}

\section{Idris Nasir Abdullahi}

Department of Medical Laboratory Science, Faculty of Allied Health Sciences, Ahmadu Bello University, Zaria, Nigeria

(iD) https://orcid.org/0000-0002-5511-1272

Corresponding author: eedris888@yahoo.com

\section{Anthony Uchenna Emeribe}

Department of Medical Laboratory Science, University of Calabar, Calabar, Nigeria

(iD) https://orcid.org/0000-0003-2937-8595

\section{Hafeez Aderinsayo Adekola}

Department of Microbiology, Olabisi Onabanjo University, Ogun state, Nigeria

(iD) https://orcid.org/0000-0003-3132-3315

\section{Habiba Yahaya Muhammad}

Department of Medical Laboratory Science, Bayero University Kano, Nigeria

(iD) https://orcid.org/0000-0001-7788-1094

\section{Abdurrahman El-fulaty Ahmad}

Department of Medical Laboratory Science, Faculty of Allied Health Sciences, Ahmadu Bello University Zaria Nigeria

(D) https://orcid.org/0000-0003-1941-8346

\section{Abubakar Umar Anka}

Department of Medical Laboratory Science, Faculty of Allied Health Sciences, Ahmadu Bello University Zaria Nigeria

(iD) https://orcid.org/0000-0001-7983-8284

\section{Shamsuddeen Haruna}

Department of Medical Laboratory Science, Faculty of Allied Health Sciences, Ahmadu Bello University Zaria Nigeria

(iD) https://orcid.org/0000-0002-8991-6685

\section{Bamidele Soji Oderinde}

Department of Medical Laboratory Science University of Maiduguri, Maiduguri, Nigeria

(D) https://orcid.org/0000-0003-4420-8607

\section{Yusuf Mohammed}

Department of Medical Microbiology and

Parasitology, Bayero University Kano, Nigeria

(iD) https://orcid.org/0000-0001-9414-9217

Halima Ali Shuwa

Department of Community Health, Federal

University Dutse, Jigawa State, Nigeria

(iD) https://orcid.org/0000-0002-7926-0360

Adamu Babayo

Department of Medical Microbiology and

Parasitology, Bayero University Kano, Nigeria

(iD) https://orcid.org/0000-0003-1039-486X

DOI: https://doi.org/10.20883/medical.408

Keywords: cellular immunity, cytokines, leishmaniasis, pro-inflammation, HIV co-infection.

Published: 2020-01-30

How to Cite: Abdullahi, I. N., A. U. Emeribe, H. A. Adekola, H. Y. Muhammad, A. E. Ahmad, A. U. Anka, S. Haruna, B. S. Oderinde, Y. Mohammed, H. A. Shuwa, and A. Babayo. "Leucocytes and Th-Associated Cytokine Profile of HIV-Leishmaniasis Coinfected Patients Attending the Abuja Teaching Hospital, Nigeria". Journal of Medical Science, vol. 89, no. 1, Jan. 2020, p. e408, doi:10.20883/medical.408.

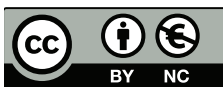

(C) 2020 by the author(s). This is an open access article distributed under the terms and conditions of the Creative Commons Attribution (CC BY-NC) licencse. Published by Poznan University of Medical Sciences

\section{ABSTRACT}

Introduction. T-helper cells (Th)-1\& -2 cytokines homeostasis control orpredict clinical outcome of infected persons, especially those with HIV /AIDS. This case-control study evaluated the leucocytes differentials, TNF-alpha, interleukin (IL)-2 and -10 levels among HIV infected persons with serological evidence of leishmaniasis attending University of Abuja Teaching Hospital, Nigeria. 
Material and Methods. Blood samples from $28 \mathrm{HIV}$ infected persons who had Leishmania donovani rK39 and IgG positive (group 1), 30 age- \& -sex matched HIV infected persons without Leishmania antibodies (group 2) and 30 apparently healthy persons without HIV and Leishmania antibodies (group 3). Full blood counts, TNF alpha, IL-2 and -10 levels were analyzed using automated hematology analyzer and ELISA, respectively. Structured questionnaires were used to collate biodata and clinical presentations of participants.

Results. Ten (35.7\%) participants in group 1 were on ART, 15 (50\%) in group 2 were on ART, while group 3 were ART naïve. There were significantly higher values in basophil (4.4 $\pm 2.5 \%)$ and eosinophil counts (12.9 $\pm 3.8 \%$ ) in HIV/leishmania coinfected persons ( $p$ 0.005). However, other white cells subpopulation was significantly lower in HIV/leishmania co-infected participants ( $p \quad 0.05)$. There was significantly reduced CD4+ T cell counts ([119 \pm 26 versus $348 \pm 63$ versus $605 \pm 116$ cells $/ \mathrm{mm} 3])$, TNF-alpha ([36.82 \pm 8.21 versus 64.67 \pm 12.54 versus $254.98 \pm 65.59 \mathrm{pg} / \mathrm{mL}])$ and IL-2 levels $([142.14 \pm 20.91$ versus $507.6 \pm 84.42$ versus $486.62 \pm$ $167.87 \mathrm{pg} / \mathrm{mL}$ ]) among HIV/Leishmania co-infected participants compared to group 2 and group 3 participants, respectively. However, higher IL-10 level $(80.35 \pm 14.57 \mathrm{pg} / \mathrm{mL})$ was found in HIV/Leishmania co-infected participants as opposed to the HIV mono-infected $(62.2 \pm 10.43 \mathrm{pg} / \mathrm{mL})$ and apparently healthy persons $(23.97 \pm 4.88 \mathrm{pg} / \mathrm{mL})(\mathrm{p} \quad 0.001)$.

Conclusion. Eosinophil, basophil counts and serum IL-10 level were high in HIV/Leishmania coinfected persons, demonstrating parasite-induced hypersensitivity and immunosuppression.

\section{Introduction}

HIV-leishmaniasis co-infection poses a major threat in people living with HIV (PLWHV) and vice versa [1]. HIV and leishmaniasis are restricted within the confined of mutual reinforcement [2]. In PLWHV, Leishmaniasis induces, hastens AIDS onset and limits lifespan [3]. Furthermore, HIV infection escalates the risk of clinical Visceral Leishmaniasis (a severe form of leishmaniasis) more than 100 times [4]. Both infections co-existence HIV-leishmaniasis co-infection increase disease burden by inhibiting $T$ helper cell-mediated immune responses $[1,4]$. In addition, there is a fundamental change in cytokine network signaling pattern $[1,4]$.

Leishmaniasis could be cutaneous (CL), mucocutaneous (ML) or Visceral (VL) depending on the etiologic species and the site or tissue/ organ affected. CL pose enormous health challenge in most global regions especially the third world countries [5]. At least 88 countries are considered endemic for leishmaniasis [6]. In sub-Saharan Africa, PLWHV are afflicted more frequently with VL as the third most common infection [7]. As a result of the VL affecting the destitute and indigent patients, under-reporting of the presented cases in several affected regions is usually due to the absence of diagnostic equipment to investigate the co-infection and to inefficient reporting systems $[1,7]$.
Importantly, Individuals living with VL-HIV coinfection are regarded as super-spreaders of $\mathrm{VL}$ infection which presents a major challenge to the efforts of eradicating leishmaniasis [1]. Based on these reasons, it was proposed that Leishmania organisms are critical in the pathogenesis of HIV-1 infection. In addition, it was observed that L. donovani amastigotes enhances HIV replication via TNF-alpha production and activates CD4+ T cells with the aid of its lipophosphoglycan [8]. Put together, it has been proven that anti-leishmanial therapy is efficacious in the inhibition of HIV replication [9]. However, the balances of proand anti-inflammatory cytokines are needed to prevent immunopathological disorders [9].

Pro-inflammatory cytokines secreted by Th1 cells are instrumental in regulating the proliferation and differentiation of T-lymphocytes in defense against HIV-leishmania co-infection. Despite the role of these cytokines, it is vital that these population is balance with their anti-inflammatory counterparts so as to avoid unpleasant immunopathological defects.

These defects which could be due to unregulated Th1 cell activity and excessive role of pro-inflammatory cytokines can have negative impact on the survival of $T$ cell clones. The $T$ cells that survive are dysfunctional and lack the ability to increase in number as well as secrete specific interferon-gamma targeted at antigenic stimuli. Previous research has shown that CD4 T lympho- 
cytes with diverse lymphokine patterns are more efficient compared to humoral B cells in reducing the burden of leishmania infection. On the other hand, the anti-inflammatory cytokines (IL-4, IL-10) when secreted by Th2 cells in discriminate proportions can promote the survival of parasites within cells and increase disease burden $[1,10]$.

A scientific study currently reported the existence of a dominant cytokine profile secreted by Th1 cells and possess high protective role for pathogens compared to Th2 cytokines in HIV infection. It has been hypothesized that a shift from Th1 to Th2 cytokines depletes CD4 population and enhances viral replication in AIDS $[9,11]$. In order to determine the expression profile of Th1 and Th2 cytokines in the case of HIV-Leishmaniasis co-infection, this study aims to investigate the plasma levels of both pro- (IL-2, interferongamma) and anti-(IL-10) inflammatory cytokines as well as white cell differentials of persons coinfected by the HIV and leishmaniasis University of Abuja Teaching Hospital, Northcentral Nigeria.

\section{Material and Methods}

\section{Study Area}

This hospital-based research was conducted at the University of Abuja Teaching Hospital (UATH) in the Federal Capital Territory (FCT), Abuja, Nigeria. Blood samples were collected at the antenatal clinics and analyzed at the Immunology laboratory. Gwagwalada is about $45 \mathrm{~km}$ away from the FCT. It is one of the six area council headquarters of the FCT. The town lies in the downstream of River Usuma and is located between latitude $8^{\circ} 55^{\prime}$ and $9^{\circ} 00^{\prime} \mathrm{N}$ and longitudinal $7^{\circ} 00^{\prime}$ and $7^{\circ} 05^{\prime} \mathrm{E}$.

The centrality of this town in relation to other area councils' headquarters makes it influential and important in various socio-economic activities. The climate condition of this town is not farfetched from that of the tropics having several climatic elements in common; most especially the wet and dry season characteristic. The temperature of the area ranges from $30^{\circ} \mathrm{C}$ to $37^{\circ} \mathrm{C}$ yearly, with the highest temperature experienced in the month of March and mean total rainfall of approximately $1650 \mathrm{~mm} / \mathrm{annum}$. The area council is an industrial zone of FCT that stands out as the second most cosmopolitan city of the FCT, after the capital city with 10 political wards and consist of over 26 Federal organizations which include University of Abuja, University of Abuja Teaching Hospital etc. These have brought about the inflow of people into the council. About $60 \%$ of Gwagwalada residents live in rural settlements and are predominately farmers.

\section{Study Design and Population}

This was a case-control study conducted between the 7th of April to the 10th of October 2015. Participants were recruited at UATH. Blood samples were collected from 28 HIV infected persons who were clinically diagnosed of VL and were rK39 and antileishmania donovani IgG seropositive (group 1), 30 age- \& -sex matched HIV infected persons without Leishmania antibodies (group 2) and 30 apparently health persons without HIV and Leishmania antibodies (group 3). All participants aged between 15 and 50 years. Unigold $\AA$ and Determine ${ }^{\circledR}$ were used to confirm the HIV status of participants. Samples from groups 1 and 2 were collected at the HIV Clinic, while samples from group 3 were collected from apparently healthy volunteers, who were interns at the University of Abuja Teaching Hospital (UATH), Gwagwalada, Abuja, Nigeria. Participants were selected by HIV/AIDS physicians and nurses. All participants were re-tested for Kala Azar rK39 and L. donovani IgG antibodies.

\section{Exclusion and Inclusion Criteria for Selection of Participants}

Only Participants who reported with no history of immune system-related diseases, absence of any recent infectious diseases, not on anti-leishmanial treatment prior to sampling, and who gave written consent were enrolled into this study.

\section{Ethical Issues and Considerations}

Ethical approval for this study was obtained from the Human Ethical Research Committee of UATH, while written consent was received either directly from participants ( $>18$ years) or via their respective parents/guardians (for those $<18$ years). Demographics were collected using structured questionnaire. Confidentiality was ensured since samples were stored pseudonymized (study code). All data were analyzed anonymously.

\section{Sample Collection and Preparation}

Five milliliter $(5 \mathrm{ml})$ of whole blood samples were collected aseptically. Two milliliters of eth- 
ylenediaminetetraacetic acid-preserved blood samples were used for CD4+ cell counts and full blood count, while $3 \mathrm{~mL}$ in lithium heparin-preserved blood was used to harvest plasma for cytokine measurement using enzyme immunoassay. Samples were collected between from 7 th April to 10th October 2015. Blood samples were analyzed within 1 hour of collection.

\section{Laboratory Analytical Procedures}

\section{White Cell Count and Differentials}

Sysmex ${ }^{\text {TM }}$ XS-1000i five parts automated hematology analyzer was used for the total white cell count, monocyte, basophils, eosinophils and lymphocyte differentials using direct current detection method with coincidence correction. The automatic discriminators separated the cell populations based on complex algorithms. The intensity of the electronic pulse from each analyzed cell was proportional to the cell volume.

\section{Flow Cytometry Assay for Lymphocyte Population}

Based on the manufacturer's instructions, the CD4+ cell counts in the whole blood were analyzed using a Partec ${ }^{\text {TM }}$ CyFlow Analyzer (Sysmex, Norderstedt, Germany) Model SL3. This device used the principle of light scattering property (based on dissimilarity in cell size or granularity) and the fluorescence of cells following staining with monoclonal antibodies to markers on the cell surface bound to fluorescent dyes. Flow cytometry data was analyzed using FlowJo v.7.6.5 software. Cell populations of interest were then gated after identification. The generated percentages were multiplied by the total number of lymphocytes in the haemogram to derive absolute values for circulating lymphocytes. Absolute CD4+ cell counts were subsequently analyzed using a single-platform technique. Values for apparently healthy participants (group 3) were used as a reference.

\section{Enzyme-linked Immunosorbent Assay for Anti- Leishmania Ig $G$ antibody}

Indirect ELISA was carried out according to the method described by kit manufacturer (product code: KA3295) (Abnova ${ }^{\circledR}$, USA). The Leishmania ELISA test is a three-incubation process whereby the first incubation involved the coating of the wells with Leishmania spp antigen. During this step, all antibodies that are reactive with the L. donovani antigens bind to the wells. Next, the wells were washed to remove test sample and other non-IgG antibodies. At this point Enzyme Conjugate was added. During this second incubation, the Enzyme Conjugate specifically bound to IgG antibodies present.

Before the third incubation step, 3 more washings were done. Then a chromogen (tetramethylbenzidine or TMB) was added. With the presence of Enzyme Conjugate and the peroxidase causing the consumption of peroxide, the chromogen changed to a blue color. The blue color turned to a bright yellow color after the addition of the stop solution, which ended the reaction. ELISA plate reader was used for the optical densities (ODs) of every well and results calculated from the ODs.

\section{Detection of Leishmania donovani rK39} antibodies by Immunochromatography This test was conducted using the Inbios ${ }^{\circledR}$ Kalazar Detect ${ }^{\mathrm{TM}}$ Rapid Test (USA). The Kalazar Detect $^{\mathrm{TM}}$ Test for VL is a qualitative, membranebased immunoassay for the detection of antibodies to Visceral Leishmaniasis in human serum. The membrane was pre-coated with rK39 on the test line region and chicken anti-protein $A$ on the control line region. During testing, the serum sample reacted with the dye conjugate (protein A-colloidal gold conjugate) which has been precoated in the test device.

The mixture then migrates upward on the membrane chromatographically and reacted with recombinant $V L$ antigen on the membrane and generates a red line. The presence of this red line indicated a positive result, while its absence indicated a negative result. Regardless of the presence of antibody to rK39, as the mixture continues to migrate across the membrane to the immobilized chicken anti-protein $A$ region, a red line at the control line region will always appear. The presence of this red line served as verification for sufficient sample volume and proper flow and as a control for the reagents. In addition, external control sera with known L. donovani result were ran alongside the samples. This test has sensitivity of $89.8 \%$ and specificity of $100 \%$.

Enzyme-linked Immunosorbent Assay for Cytokines ELISAwas carried out according to the method described by kit manufacturer (Abcam ${ }^{\circledR}$, UK). 
Accordingly, IL-2 (product code: ab174444), IL-10 (product code: ab100549) and TNF-alpha (product code: ab181421) were investigated.

The Simple-step ELISA ${ }^{\circledR}$ employs an affinity tag labeled capture antibody and a reporter conjugated detector antibody which immunocapture the sample analyte in solution. This entire complex (capture antibody/analyte/detector antibody) is in turn immobilized via immunoaffinity of an anti-tag antibody coating the well. To perform the assay, samples or standards were added to the wells, followed by the antibody mix. After incubation, the wells were washed to remove unbound material. TMB Development Solution was added and during incubation the reaction was catalyzed by HRP, generating blue coloration. This reaction was then stopped by addition of Stop Solution completing any color change from blue to yellow. Signal is generated proportionally to the amount of bound analyte and the intensity was measured at $450 \mathrm{~nm}$.

\section{Statistical analysis}

SPSS (version 24, IBM Corporation, USA) was used to analyze data which was expressed as mean $\pm S D$ and statistical significance was considered for $p$-values $\leq 0.05$. One-way ANOVA was used to compare categorical variables. $P$ values < 0.05 at a confidence interval of $95 \%$ were considered statistically significant.

\section{Results}

HIV-Leishmaniasis co-infected participants showed preponderance of female gender The evaluation of the preponderance of female gender on the basis of the ratio of all the participant groups (1-3), indicated that the female to male ratio (19:9) was mainly maximum in participants co-infected with HIV and Leishmaniasis.
The mean \pm SD age of participants was $26.6 \pm 4.9$ years, $28.2 \pm 5.8$ years, and $26.9 \pm 5.1$ years for groups 1, 2 and 3, respectively. Only 10 (35.7\%) participants in group were on ART, $15(50 \%)$ in group 2 were on ART, while group 3 were ART naïve (Table 1).

HIV-Leishmaniasis co-infected participants indicated varied leukocyte profile concentrations in whole blood

Serum levels of neutrophil $(p=0.04)$, and lymphocytes $(p=0.001)$, where significantly decreased in Leishmania-HIV co-infected participants compared to the HIV mono-infected participants. On the other hand, the serum levels of basophils ( $p=$ $0.001)$, eosinophils $(p=0.001)$, and monocytes ( $p$ $=0.001$ ) where significantly raised in the Leishmania-HIV co-infected group of participants as opposed to the HIV mono-infected group of participants (Table 2).

\section{CD4+ $T$ cell population decline in response to} HIV-Leishmaniasis

CD4+ $T$ cell population significantly $(p=0.001)$ decreased in participants with HIV/Leishmaniasis co-infection compared to their HIV-monoinfected counterparts. All HIV sero-positive participants with or with anti-Leishmania antibodies had their CD4+ T-lymphocyte below the reference lower limit of 500 cells $/ \mathrm{mm} 3$ (Table 3).

HIV-Leishmaniasis co-infected participants showed varied cytokine profile in plasma In a similar case with $\mathrm{CD} 4+\mathrm{T}$ cell population, pro-inflammatory cytokines [IL-2 $(p=0.001)$ and TNF-alpha $(p=0.001)]$ significantly decreased, while ant-inflammatory cytokine [IL $=10(p=$ 0.001)] significantly increased in participants with HIV/Leishmaniasis co-infection compared to their HIV-mono-infected counterparts. On the other hand, significantly increased serum levels of anti-inflammatory cytokine (IL-10 ( $p=0.001))$

Table 1. Demographic of participants with and without anti-Leishmania donovani seropositivity

\begin{tabular}{lccc} 
Variable & $\begin{array}{c}\text { HIV and Leishmania } \\
\text { Coinfected Persons } \\
(\mathbf{n = 2 8 )}\end{array}$ & $\begin{array}{c}\text { HIV Infected Persons without } \\
\text { Leishmania antibodies } \\
(\mathbf{n}=\mathbf{3 0})\end{array}$ & $\begin{array}{c}\text { Persons without HIV and } \\
\text { Leishmania antibodies } \\
(\mathbf{n}=\mathbf{3 0})\end{array}$ \\
\hline $\begin{array}{l}\text { Age (years) } \\
\text { Mean } \pm \text { SD }\end{array}$ & $26.6 \pm 4.9$ & $28.2 \pm 5.8$ & $26.9 \pm 5.1$ \\
\hline Male to female ratio & $9: 19$ & $9: 21$ & $9: 21$ \\
\hline $\begin{array}{l}\text { Number of participants on } \\
\text { ART }\end{array}$ & 9 & 15 & 0 \\
\hline
\end{tabular}


Table 2. Comparison of White cell count and differentials of participants with and without Leishmania donovani seropositivity

\begin{tabular}{|c|c|c|c|c|c|}
\hline \multirow[t]{2}{*}{ Parameter } & \multicolumn{3}{|c|}{ Value (mean \pm SD) } & \multirow[t]{2}{*}{ F-value } & \multirow[t]{2}{*}{$\mathrm{p}$-value } \\
\hline & $\begin{array}{l}\text { HIV and Leishmania } \\
\text { Coinfected Persons } \\
\qquad(\mathrm{n}=28)\end{array}$ & $\begin{array}{l}\text { HIV Infected Persons } \\
\text { without Leishmania } \\
\text { antibodies } \\
(\mathbf{n}=\mathbf{3 0})\end{array}$ & $\begin{array}{l}\text { Persons without HIV and } \\
\text { Leishmania antibodies } \\
\qquad(\mathrm{n}=30)\end{array}$ & & \\
\hline WBC $10^{9} / \mathrm{L}$ & $3.7 \pm 1.2$ & $4.2 \pm 1.9$ & $5.9 \pm 2.1$ & 12.23 & 0.0001 \\
\hline Neutrophils (\%) & $58.9 \pm 11.6$ & $61.6 \pm 10.4$ & $64.1 \pm 13.2$ & 5.834 & 0.040 \\
\hline Lymphocytes (\%) & $22.5 \pm 9.8$ & $29.9 \pm 10.6$ & $30.7 \pm 9.9$ & 9.994 & 0.001 \\
\hline Basophils (\%) & $4.4 \pm 2.5$ & $3.1 \pm 1.2$ & $1.4 \pm 0.8$ & 11.01 & 0.001 \\
\hline Eosinophils (\%) & $12.9 \pm 3.8$ & $4.3 \pm 2.6$ & $3.2 \pm 2.3$ & 62.63 & 0.001 \\
\hline Monocytes (\%) & $1.3 \pm 3.5$ & $1.1 \pm 0.2$ & $0.6 \pm 0.1$ & 13.97 & 0.001 \\
\hline
\end{tabular}

Table 3. Comparison of Cytokines and $\mathrm{CD} 4+\mathrm{T}$ cell count and differentials of participants with and without Leishmania donovani seropositivity

\begin{tabular}{lccccc}
\multicolumn{1}{c}{ Parameter } & \multicolumn{3}{c}{ Value $($ mean \pm SD) } & F value & p-value \\
\cline { 2 - 5 } & $\begin{array}{c}\text { HIV and Leishmania } \\
\text { Coinfected Persons }(\mathbf{n}= \\
\mathbf{2 8})\end{array}$ & $\begin{array}{c}\text { HIV Infected Persons } \\
\text { without Leishmania } \\
\text { antibodies }(\mathbf{n}=\mathbf{3 0})\end{array}$ & $\begin{array}{c}\text { Persons without HIV } \\
\text { and Leishmania } \\
\text { antibodies }(\mathbf{n}=\mathbf{3 0})\end{array}$ & & \\
\hline $\mathrm{CD} 4+\mathrm{T}$ cell count $\left(\right.$ cells $\left./ \mathrm{mm}^{3}\right)$ & $119 \pm 26$ & $348 \pm 63$ & $605 \pm 116$ & 278.0 & 0.001 \\
\hline $\mathrm{IL}-2(\mathrm{pg} / \mathrm{ml})$ & $142.14 \pm 20.91$ & $507.6 \pm 84.42$ & $486.62 \pm 167.87$ & 291.0 & 0.001 \\
\hline $\mathrm{IL}-10(\mathrm{pg} / \mathrm{ml})$ & $80.35 \pm 14.57$ & $62.2 \pm 10.43$ & $23.97 \pm 4.88$ & 211.0 & 0.001 \\
\hline $\mathrm{TNF}-\mathrm{alpha}(\mathrm{pg} / \mathrm{ml})$ & $36.82 \pm 8.21$ & $64.67 \pm 12.54$ & $254.98 \pm 65.59$ & 269.0 & 0.001 \\
\hline
\end{tabular}

was observed in the Leishmania-HIV co-infected participants as opposed to the HIV mono-infected participants (Table 3 ).

\section{Discussion}

Leishmania/HIV's capability to influence host cellular immunity and co-exist in the lymphoid tissues indicates their ability to mutually communicate by mutually re-enforcing their replication when co-existing in the same host cells [11]. To the best of our knowledge, this is one of a few studies that demonstrates for the first time the influence of the interaction of these pathogens on cytokines and leukocytes which are orchestrators of the host defense system and play vital functions in modulating the host immune response against Leishmania/HIV co-infection. Comparative analysis of leukocyte and cytokine profiles from co- and mono-infected participants highlighted significant variations in immune response mounted against co-infection, confirming the ability of Leishmania and HIV to mutually interact at the immunological level.

Participants co-infected with Leishmania and HIV responded with an overall decrease in proinflammatory cytokine (IL-2, TNF-alpha) and the increase in anti-inflammatory cytokine (IL-10) release. Low level of these pro-inflammatory cytokines have been reported in Indian patients with active Leishmaniasis and elevated levels observed in those treated of Leishmaniasis [12]. IL-2 and TNF-alpha have been implicated in protective immunity towards parasitic and viral infections [13]. TNF-alpha, a vital mediator of both innate and adaptive inflammatory responses [14], is observed to possess a crucial role in the formation and maintenance of granuloma against visceral leishmania. This anti-parasitic function of TNF-alpha is mediated by the activation of infected macrophages for the killing of intracellular Leishmania amastigote [15]. IL-2, which is produced by activated CD4+ Th cells and was formally referred to as "T-cell growth factor", have been thought to induce the proliferation and differentiation of Th2 cells (B-cells, natural killer cells, monocyte/macrophages, oligodendrocytes and lymphocyte activated killer cells) and aid in the release of IgG1 and IgE-producing cells which is vital for the resolution Leishmaniasis [16], suggesting that this cytokine may be crucial for Leishmania clearance. Hence decreased concentrations of IL-2 observed in the co-infected versus the mono-infected cohort, apart from the already diminished levels of TNFalpha, may be indicative of a non-favourable, poor prognosis for Leishmania. 
However, an increase in the level of IL-10 (an anti-inflammatory cytokine), and reduction in cell-mediated immunity are seen in Leishmania infection. IL-10 dampens the production of many pro-inflammatory cytokines (including TNF-alpha, IL-1, IL-6, and IL-12), it also decreases the expression of MHC-II and other co-stimulatory molecules on the surface of macrophages, and these inhibit macrophage-mediated activation of CD4+ helper T cells leading to a reduction in both adaptive and innate immune responses [17].

The immunosuppressive role of $\mathrm{IL}-10$ in human visceral leishmaniasis leads to a drastic decrease in the accumulation of monocytederived macrophages, which is controlled by the migration inhibition factor. Furthermore, IL-10 is observed to encourage the Th1 cell dysfunction which enhance intracellular infection for interferon-gamma production, deactivating parasitized tissue macrophages, and downregulating antigen presentation by dendritic cells [17].

IL-10 have also been implicated in inhibiting the leishmanicidal roles of macrophages by decreasing the synthesis and release of pro-inflammatory molecules (reactive nitrogen intermediates by macrophages, interferon-gamma by $\mathrm{T} /$ natural killer cells, and IL-12 mediated activation of macrophages). These suppressive roles of IL-10 which is released by alternatively activated macrophages and interferon-gamma co-producing CD4+ T cells (type 1 regulatory T cells) at moderate to high levels due to the low to zero levels of pro-inflammatory cytokines and the decreased number of multifunctional CD4+ T cells [17]. During the initial phases of infection justifies why it is associated with decreased immunity against Leishmania infection. Due to suppressive role of IL-10, the parasite burden continues to build up even when interferon-gamma levels are elevated [18].

In addition to the varying levels of cytokine profile, this study revealed a higher secretion of IL-10 which was associated with increased viremia and depleted CD4+ T cell population in Leishmania/HIV co-infected participants compared to those of the HIV mono-infected group. This corroborated with a recent study, which reported CD4+ T cell count as low as 49 cells/mm3 in HIV/ Leishmaniasis asymptomatic immune responders compared to the non-responders [19]. The marked fall in CD4+ T cell number is associated with the reduced leishmanicidal capacity of mac- rophages, and the replication and uncontrolled systemic spread of the parasite throughout the body [20] which increases the risk of progression to visceral leishmaniasis by 100 to 2320 times based on the mutual interaction between HIV and Leishmania [21].

Based on the leukocyte profile, HIV/Leishmania co-infected participants had significantly lower lymphocyte and neutrophil counts with significantly higher monocyte, basophil and eosinophil counts as observed in this study. These observations were in line with a study conducted in Brazil [22] which demonstrated significantly lower levels of lymphocyte and haemoglobin counts at diagnosis, and considerably higher levels of eosinophil count in the initial hematologic evaluation in over $50 \%$ of co-infected participants. Similar observations were observed in the liver of genetically susceptible mice infected with experimental visceral leishmaniasis [19].

The primary cells of mice that are infected by Leishmania donovani amastigotes are the liver resident tissue macrophages (Kupffer cells). These cells are observed to produce cytokine sand chemokines which recruit monocytes and neutrophils to the infection site during the initial days of infection, thus, further amplifying the production of more chemokines [23]. Neutrophils (primary antimicrobial cells) control infections by phagocytising and killing invading pathogens. While some of these pathogens are killed by the lysosomal effect of the neutrophil, others which are either obligate or facultative intracellular organism become resistant to the lysosomal enzymes and replicate in these cells which become apoptotic. These apoptotic neutrophils (without parasiticidal effect) either control Leishmania growth by undergoing depletion to reduce the load of this parasite and delaying the onset of leishmaniasis [24] or act as Trojan horses with delayed apoptosis by the parasite for onward transmission, infection and replications of these parasites in monocytes and macrophages that phagocytize the infected apoptotic neutrophils.

Another exciting outcome observed in this study is the decrease in neutrophil count. Leishmania infection interferes with several signaling pathways in immune cells [25]. Monocytes have been observed to possess antiparasitic function based on their plasticity and ability to differentiate into potent antigen-presenting or regulatory 
cells [26]. The recruitment of neutrophils, monocytes, and then the T cells into the Kupffer cells is crucial for the formation of granuloma around these cells which is required for controlling the growth of Leishmania/HIV co-infection [27].

The cellular immune-mediated interactions between Leishmania spp and HIV seem to determine the extent of immunological response that occur in the co-infected biological system as well as the intensity of the onset of the accompanying infection. Similar circumstances have been observed with other Leishmania co-infections, revealing that the inherent consequences that emerge from several pathogen-host relations need to resolve when designing Leishmania vaccine trials. Proper consideration of parasite interplays should be adopted when determining the best strategy for the treatment of LeishmaniaHIV co-infections to achieve immune stability without inflicting harm during the clinical course of the infected individual.

\section{Acknowledgements}

Authors appreciate Head of Immunology Laboratory of University of Abuja Teaching Hospital for Logistic and technical support.

\section{Conflict of interest statement}

The authors declare no conflict of interest.

\section{Funding sources}

There are no sources of funding to declare.

\section{References}

1. Adriaensen W, Dorlo TPC, Vanham G, Kestens L, Kaye PM, van Griensven J. Immunomodulatory Therapy of Visceral Leishmaniasis in Human Immunodeficiency Virus-Coinfected Patients. Frontiers in Immunology. 2018 Jan 12;8. https://doi.org/10.3389/ fimmu.2017.01943

2. Monge-Maillo B, Norman FF, Cruz I, Alvar J, LópezVélez R. Visceral Leishmaniasis and HIV Coinfection in the Mediterranean Region. Valenzuela JG. PLoS Neglected Tropical Diseases. 2014 Aug 21;8(8):e3021. https://doi.org/10.1371/journal.pntd.0003021

3. Lindoso JA, Cota GF, da Cruz AM, Goto H, MaiaElkhoury ANS, Romero GAS, de Sousa-Gomes ML, Santos-Oliveira JR, Rabello A. Visceral Leishmaniasis and HIV Coinfection in Latin America. Valenzuela JG. PLoS Neglected Tropical Diseases. 2014 Sep 18;8(9):e3136. https://doi.org/10.1371/journal. pntd.0003136

4. Craft N, Ezra N, Ochoa MT. Human immunodeficiency virus and leishmaniasis. Journal of Global Infectious Diseases. 2010;2(3):248. https://doi. org/10.4103/0974-777x.68528
5. de Vries HJC, Reedijk SH, Schallig HDFH. Cutaneous Leishmaniasis: Recent Developments in Diagnosis and Management. American Journal of Clinical Dermatology. 2015 Feb 17;16(2):99-109. https://doi. org/10.1007/s40257-015-0114-z

6. WHO Report on Global Surveillance of Epidemicprone Infectious Diseases - Leishmaniasis. https:// www.who.int/csr/resources/publications/CSR ISR_2000_1leish/en/. Accessed 2019 August 20.

7. Shafiei R, Mohebali M, Akhoundi B, Galian MS, Kalantar F, Ashkan S, Fata A, Hosseini Farash BR, Ghasemian M. Emergence of co-infection of visceral leishmaniasis in HIV-positive patients in northeast Iran: A preliminary study. Travel Medicine and Infectious Disease. 2014 Mar;12(2):173-178. https://doi. org/10.1016/j.tmaid.2013.09.001

8. Forestier C, Gao Q, Boons G. Leishmania lipophosphoglycan: how to establish structure-activity relationships for this highly complex and multifunctional glycoconjugate?. Frontiers in Cellular and Infection Microbiology. 2015 Jan 21;4. https://doi.org/10.3389/ fcimb.2014.00193

9. Rodrigues MZA, Grassi MFR, Mehta S, Zhang X, Gois LL, Schooley RT, Badaro R. Th1/Th2 Cytokine Profile in Patients Coinfected with HIV and Leishmania in Brazil. Clinical and Vaccine Immunology. 2011 Aug 10;18(10):1765-1769. https://doi.org/10.1128/ cvi.00076-11

10. Gois LL, Mehta S, Rodrigues MZA, Schooley RT, Badaró R, Grassi MFR. Decreased memory T-cell response and function in human immunodeficiency virus-infected patients with tegumentary leishmaniasis. Memórias do Instituto Oswaldo Cruz. 2014 Feb;109(1):9-14. https://doi.org/10.1590/00740276130174

11. Andargie TE, Diro Ejara E. Pro- and Anti-inflammatory Cytokines in Visceral Leishmaniasis. Journal of Cell Science \& Therapy. 2016;6(2). https://doi. org/10.4172/2157-7013.1000206

12. Abbas AK, Lichtman A, Pillai S. Cellular and Molecular Immunology 7th Edition. Philadelphia: Elsivier; 2012.

13. Costa ASA, Costa GC, Aquino DMCD, Mendonça VRRD, Barral A, Barral-Netto $M$, Caldas ADJM. Cytokines and visceral leishmaniasis: a comparison of plasma cytokine profiles between the clinical forms of visceral leishmaniasis. Memórias do Instituto Oswaldo Cruz. 2012 Sep;107(6):735-739. https:// doi.org/10.1590/s0074-02762012000600005

14. Dayakar A, Chandrasekaran S, Kuchipudi SV, Kalangi SK. Cytokines: Key Determinants of Resistance or Disease Progression in Visceral Leishmaniasis: Opportunities for Novel Diagnostics and Immunotherapy. Frontiers in Immunology. 2019 Apr 5;10. https://doi.org/10.3389/fimmu.2019.00670

15. Murray HW, Jungbluth A, Ritter E, Montelibano C, Marino MW. Visceral Leishmaniasis in Mice Devoid of Tumor Necrosis Factor and Response to Treatment. Mansfield JM. Infection and Immunity. 2000 Nov 1;68(11):6289-6293. https://doi.org/10.1128/ iai.68.11.6289-6293.2000

16. Stegall T. Cytokines, Clinical Immunology \& Serology (4th edn). Philadelphia: F.A. Davis Company; 2010. 
17. Nylén S, Sacks D. Interleukin-10 and the pathogenesis of human visceral leishmaniasis. Trends in Immunology. 2007 Sep;28(9):378-384. https://doi. org/10.1016/j.it.2007.07.004

18. Mesquita I, Ferreira C, Barbosa AM, Ferreira CM, Moreira D, Carvalho A, Cunha C, Rodrigues F, DinisOliveira RJ, Estaquier J, Castro AG, Torrado E, Silvestre $R$. The impact of IL-10 dynamic modulation on host immune response against visceral leishmaniasis. Cytokine. 2018 Dec;112:16-20. https://doi. org/10.1016/j.cyto.2018.07.001

19. Botana L, Ibarra-Meneses AV, Sánchez C, Castro A, San Martin JV, Molina L, Ruiz-Giardin JM, Carrillo $\mathrm{E}$, Moreno J. Asymptomatic immune responders to Leishmania among HIV positive patients. Rafati S. PLOS Neglected Tropical Diseases. 2019 Jun 3;13(6):e0007461. https://doi.org/10.1371/journal. pntd.0007461

20. Okwor I, Uzonna JE. The immunology of Leishmania/ HIV co-infection. Immunologic Research. 2013 Mar 16;56(1):163-171. https://doi.org/10.1007/s12026-0138389-8
21. van Griensven J, Carrillo E, López-Vélez R, Lynen $\mathrm{L}$, Moreno J. Leishmaniasis in immunosuppressed individuals. Clinical Microbiology and Infection. 2014Apr;20(4):286-299. https://doi.org/10.1111/14690691.12556

22. Henn GADL, Ramos Júnior AN, Colares JKB, Mendes LP, Silveira JGC, Lima AAF, Aires BP, Façanha MC. Is Visceral Leishmaniasis the same in HIV-coinfected adults?. The Brazilian Journal of Infectious Diseases. 2018 Mar;22(2):92-98. https://doi.org/10.1016/j. bjid.2018.03.001

23. Smelt SC, Cotterell SEJ, Engwerda CR, Kaye PM. B Cell-Deficient Mice Are Highly Resistant to Leishmaniadonovani Infection, but Develop NeutrophilMediated Tissue Pathology. The Journal of Immunology. 2000 Apr 1;164(7):3681-3688. https://doi. org/10.4049/jimmunol.164.7.3681

24. McFarlane E, Perez C, Charmoy M, Allenbach C, Carter KC, Alexander J, Tacchini-Cottier F. Neutrophils Contribute to Development of a Protective Immune Response during Onset of Infection with Leishmania donovani. Infection and Immunity. $2007 \mathrm{Dec}$ 3;76(2):532-541. https://doi.org/10.1128/iai.01388-07. 